\title{
PHOTOCHEMICAL PROTON GENERATION MECHANISM FROM ONIUM SALTS
}

\author{
MINORU TSUDA and SETSUKO OIKAWA
}

Laboratory of Bio-physical Chemistry, Faculty of Pharmaceutical Sciences, Chiba University, Chiba 260, JAPAN

A new mechanism which is simple and common for all onium salts were proposed on the photochemical proton generation process in resist systems, from the theoretical aspect based on quantum chemical calculations. The primary product generated from the photochemical reaction is an aryl cation $\mathrm{Ar}^{+}$, i.e., for aryldiazonium salts [Figs. 2 and 3]:

for diaryliodonium salts:

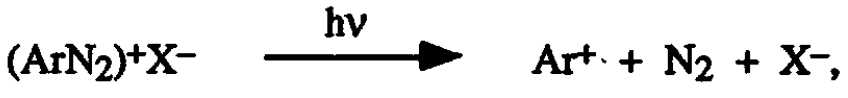

$$
\left(\mathrm{Ar}_{2} \mathrm{I}^{+} \mathrm{X}^{-} \stackrel{\mathrm{hv}}{\longrightarrow} \mathrm{Ar}^{+}+\mathrm{ArI}+\mathrm{X}^{-},\right.
$$

for triarylsulfonium salts [Table 1]:

$$
\left(\mathrm{Ar}_{3} \mathrm{~S}\right)^{+\mathrm{X}^{-}} \stackrel{\mathrm{hv}}{\longrightarrow} \mathrm{Ar}^{+}+\mathrm{Ar}_{2} \mathrm{~S}+\mathrm{X}^{-}
$$

where $\mathrm{X}^{-}$is $\mathrm{SbF}_{6}, \mathrm{AsF}_{6}, \mathrm{PF}_{6}, \mathrm{BF}_{6}, \mathrm{CF}_{3} \mathrm{SO}_{3}^{-}$, etc. The secondary proton generation reactions are [Figs. 4, 5 and 6],

$$
\begin{aligned}
\mathrm{Ar}^{+}+\mathrm{H}_{2} \mathrm{O}[\mathrm{ROH}] & \longrightarrow\left(\mathrm{ArOH}_{2}\right)^{+}\left[(\mathrm{ArOHR})^{+}\right] \\
\left(\mathrm{ArOH}_{2}\right)^{+}\left[(\mathrm{ArOHR})^{+}\right] & \longrightarrow \mathrm{ArOH}[\mathrm{ArOR}]+\mathrm{H}^{+} \mathrm{X}^{-}
\end{aligned}
$$

where $\mathrm{H}_{2} \mathrm{O}$ and $\mathrm{ROH}$ are a water molecule at the air interface and such protic species as novolak, poly(vinylphenol), poly(vinylalcohol), etc., respectively. Since the chemical amplification in resist systems originates from the photochemically generated acid $\mathrm{H}^{+} \mathrm{X}^{-}$, we can conclude from this research that the sensitivity of an onium salt as a photo-initiator is determined by the species of its anionic part $\mathrm{X}^{-}$. This conclusion is consistent with experiments where the sensitivity decreases in the order $\mathrm{SbF}_{\sigma}>\mathrm{PF}_{\sigma}>\mathrm{BF}_{6}$. 


\section{Introduction}

Onium salts, i.e., aryldiazonium salts, diaryliodonium salts, triarylsulfonium salts, etc., are important as photosensitive materials of chemical amplification resists. However, their photochemical reaction mechanisms in the generation of protons, which perform the chemical amplification in the resist process, remain obscure; and a complicated and specific mechanism for each of onium salts, which was estimated from experiments, appears currently in technical papers . For aryldiazonium salts, the acid generation mechanism in coatings and resist systems has been written as follows, ${ }^{1,2)}$ e.g.,

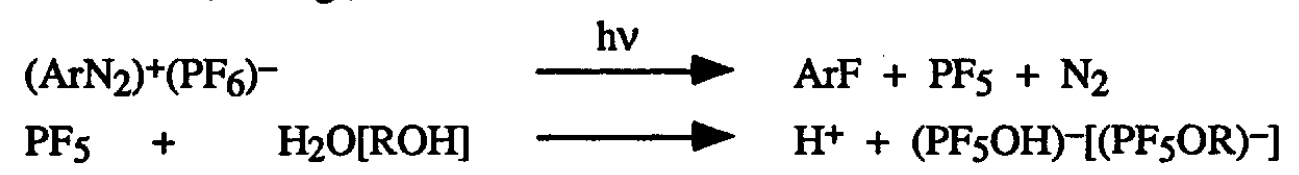

Because of the presence of water at the air interface as well as such protic species as novolac, poly(vinylalcohol), poly(vinylphenol), etc, as a binder, the reaction (2) is particularly important in coatings and resist systems. ${ }^{1)}$ This mechanism postulates a priori formation of ArF, but it has been known that phenols and esters are produced from aryldianozium salts in water and alcohols, respectively, and not ArF by photo-irradiations or heatings. ${ }^{3)}$ Halogenated products are generated only when aromatic diazonium salts are in non-reactive solvents. ${ }^{3)}$ These results strongly suggest that ArF is not a primary product in the photochemical reaction but a secondary product in a succeeded reaction, and the primary product reacts predominantly with water or alcohol when these protic species co-exist. For these reasons, the reaction (1) in the presence of water or protic binders should be written in the following formula.

$$
\left(\mathrm{ArN}_{2}\right)^{+}\left(\mathrm{PF}_{6}\right)^{-}+\mathrm{H}_{2} \mathrm{O}[\mathrm{ROH}] \stackrel{\mathrm{hv}}{\longrightarrow} \mathrm{ArOH}[\mathrm{ArOR}]+\mathrm{N}_{2}+\mathrm{H}^{+}+\left(\mathrm{PF}_{6}\right)^{-}
$$

For diaryliodonium salts and triarylsulfonium salts, current mechanisms of the photochemical proton generation are the reactions (4)-(6) and the reactions (7)-(9), respectively, where $\mathrm{PF}_{6}{ }^{-}$and $\mathrm{H}_{2} \mathrm{O}[\mathrm{ROH}]$ were used for reader's convenience instead of the original notations $\mathrm{X}^{-}$and $\left.\mathrm{RH}, 1,2\right)$

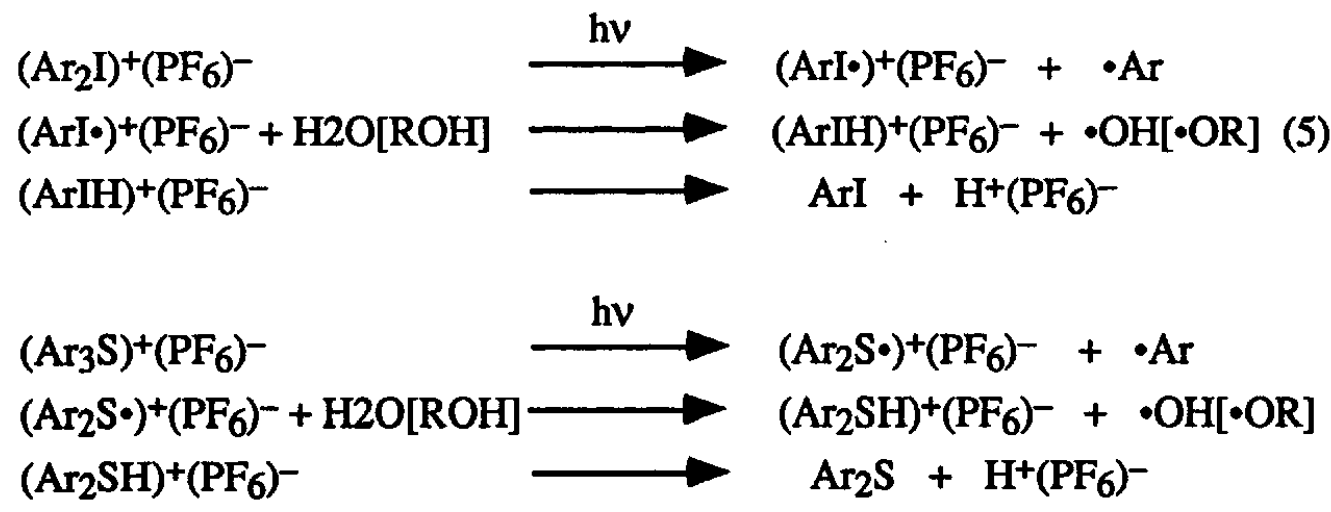

These proton generation mechanisms are entirely different from that of aryl diazonium salt [the reactions (1) and (2)]. The primary products in the photochemical process are an aryl radical, a 
cation radical ( $\mathrm{ArI} \bullet^{+}$or $\mathrm{Ar}_{2} \mathrm{~S} \bullet^{+}$) and $\mathrm{PF}_{6}$ in these cases although $\mathrm{ArF}^{\circ}$ and $\mathrm{PF}_{5}$ in the diazonium case. In this paper, these complicated proton generation mechanisms from onium salts were criticized from the quantum chemical aspect, and a new mechanism which is simple and common for all onium salts were proposed.

\section{Method}

Quantum chemical calculations are carried out by ab initio molecular orbital (MO) method except for the photochemical reaction pathway of benzene diazonium cation. All the molecular geometries are fully optimized by the energy gradient method. The basis set used is a split-valence type GTO set, 3-21G. The Hartree-Fock energies obtained are further elaborated by the second, the third and the fourth order Moeller-Plesset perturbation theory. The computational program used is GAUSSIAN 82.4)

For the potential energy change following the photochemical decomposition pathway of benzene diazonium cation, a semi-empirical SCF MO configuration interaction (CI) method is adapted with the INDO/S parametrization, ${ }^{5)}$ where the state functions are expressed in the linear combination of singly and doubly excited electronic configurations whose energies are less than $14 \mathrm{eV}$.

\section{Results and Discussion}

\section{Electronic Excitations of Benzene diazonium Salt by Photo-irradiation}

Benzene diazonium hexafluoroborate has a strong absorption peak at $260 \mathrm{~nm}$ and a small peak at $320 \mathrm{~nm}$ as shown in Fig. 1. Since this absorption spectrum is reproduced well by quantum chemical calculations, the characters of these electronic states which originate from the photo-absorptions are established. The main absorption peak at $260 \mathrm{~nm}$ has an intramolecular charge transfer character between benzene ring and diazo group with a transition moment along the long axis of the molecule. The satellite peak at $320 \mathrm{~nm}$ is corresponding to a localized excitation in benzene ring. For this reason, it is estimated that the main peak at $260 \mathrm{~nm}$ makes a dominant contribution to the photochemical decomposition of this molecule.

\section{Behaviors of Benzene diazonium Salt in Photochemical Decomposition Process in} Resist Systems

A cationic part and an anionic part of aryldiazonium salt may separate in polar solvents and be surrounded by solvent molecules. We can suppose the same situation in coatings and in resists systems whose protic binder polymers are mixed with diazonium salts. The potential energy change $\left.{ }^{6}\right)$ following the photochemical decomposition of an excited benzene diazonium cation, which is generated from the photo-absorption at $260 \mathrm{~nm}$, is shown in Fig. 2. The result indicates that the decomposition completes substantially when the bond distance between a diazo group and a benzene ring becomes $2.1 \mathrm{~A}$. 


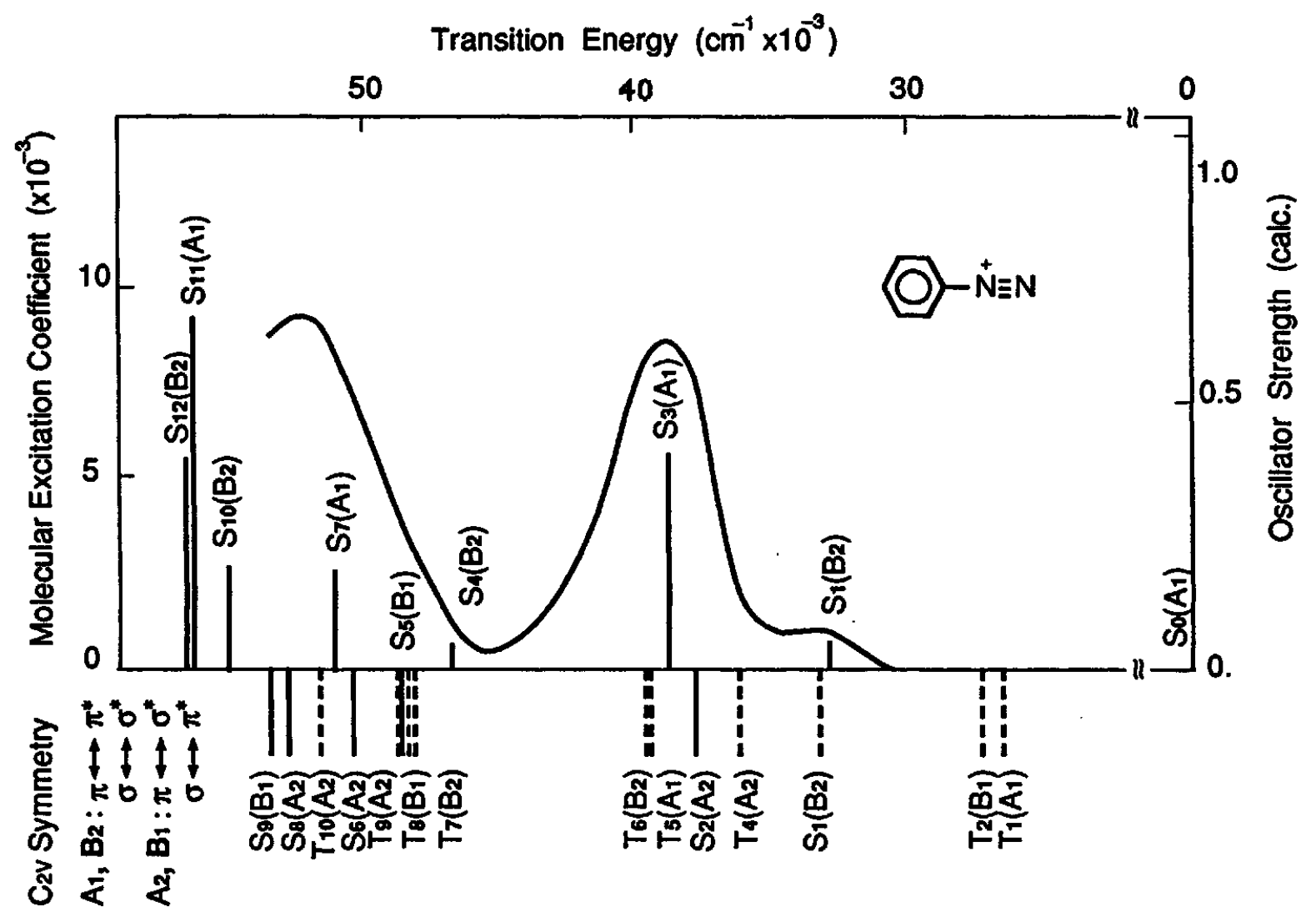

Fig. 1. UV absorption spectrum of benzene diazonium fluoroborate in ethanol with the transition energy calculated by INDO/S SCF MO CI method. The solid line shows the energy level of the excited singlet state and the dotted line that of the triplet state, respectively. The length of the solid line is proportional to the oscillator strength of the allowed transition, $A_{1}$ and $B_{1}$. For the forbidden transition, only the energy level is shown under the frame of the chart. $A_{1}, A_{2}, B_{1}$, and $B_{2}$ are the irreducible representations in $\mathrm{C}_{2 \mathrm{v}}$ symmetry.

The Primary Produced Species in Photochemical Decompositions of Aryldiazonium Salts

Potential energy changes ${ }^{6}$ ) following the decomposition process of benzene diazonium cation for the ground, the lowest triplet, the lowest excited singlet and the second lowest excited singlet states are shown in Fig. 3. The primary products in all cases are a nitrogen molecule in its ground state and a phenyl cation. This result is in accordance with experiments ${ }^{3)}$ that the final product in the 


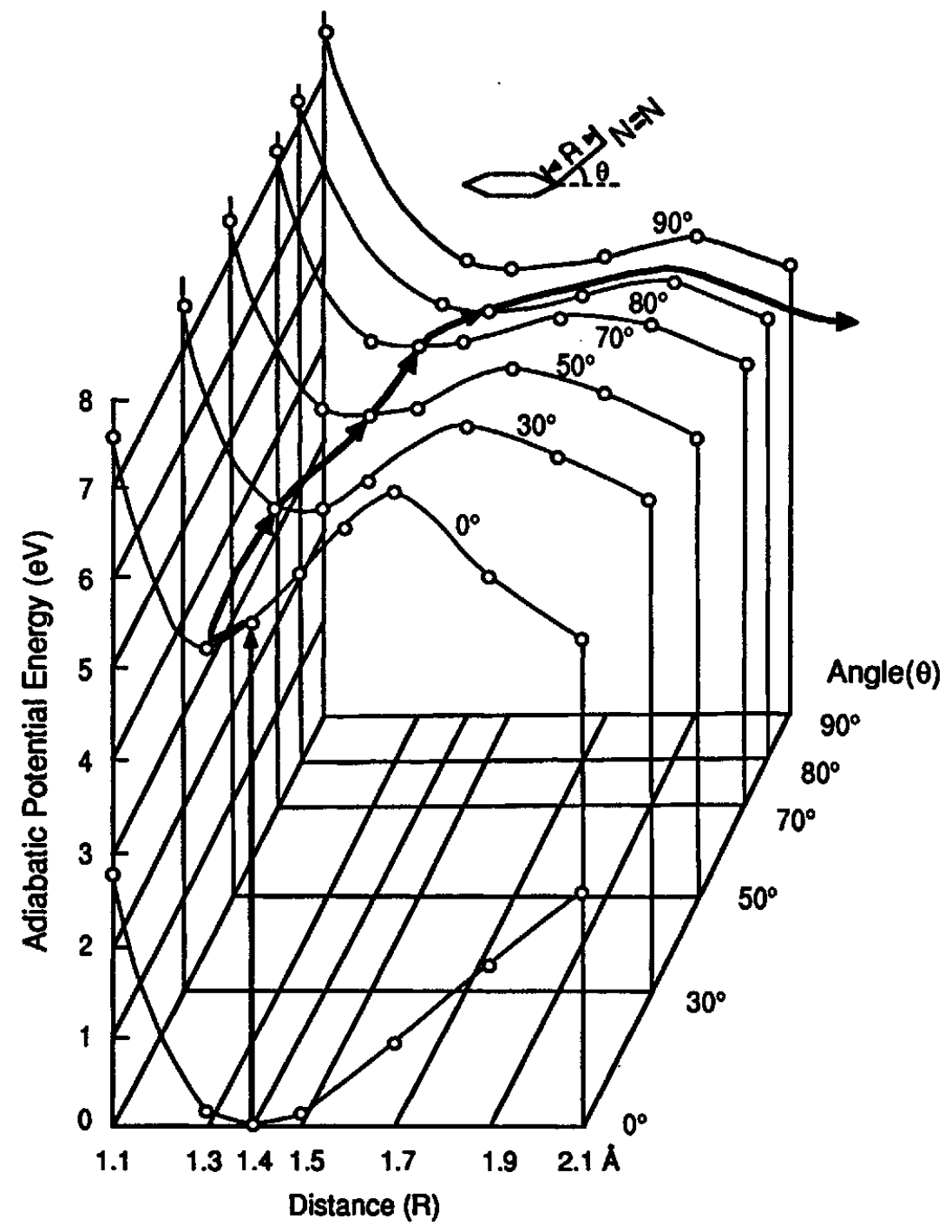

Fig. 2. Potential energy surface of benzene diazonium cation in the excited singlet state arisen from the main absorption of UV spectrum. Variable parameters are taken from the $\mathrm{C}-\mathrm{N}$ bond distance $R$ and the bending angle $\theta$. The thick curve with arrows shows the photodecomposition pathway starting from the photoabsorption.

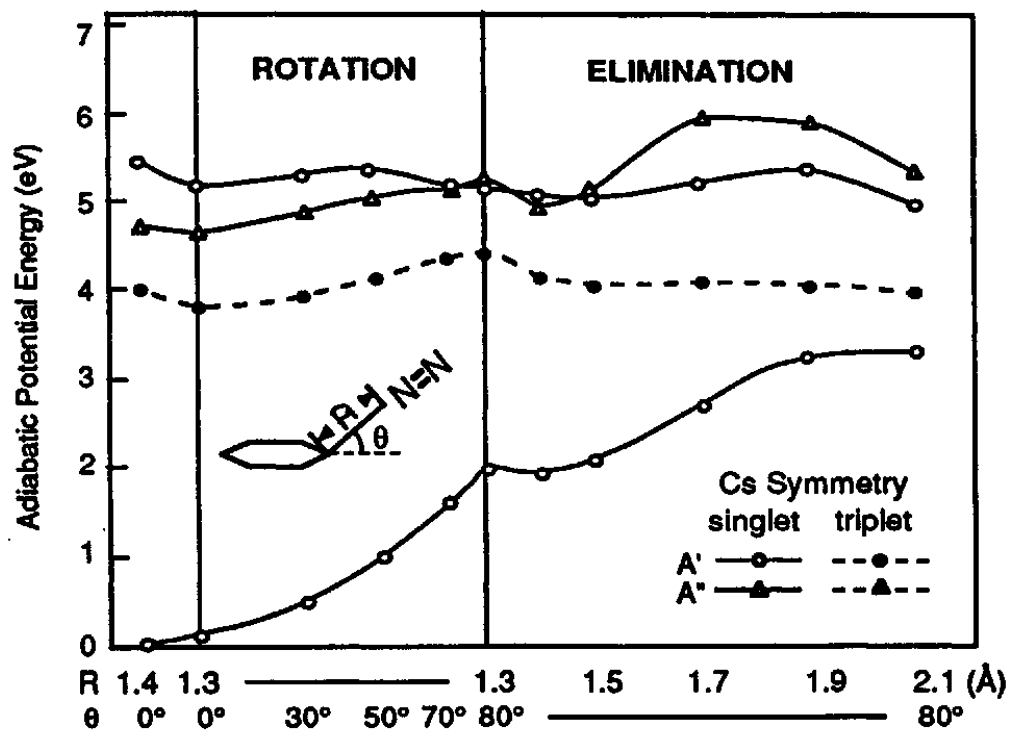

Fig. 3. Potential energy changes along the photo-decomposition reaction pathways of benzene diazonium cation in various lower excited states as well as in the ground state. Variable parameters are taken from the $\mathrm{C}-\mathrm{N}$ bond distance $R$ and the bending angle $\theta$. 
photochemical decomposition of aryldiazonium salts depends upon the circumstances where the reaction occurs.

Since the main absorption peak at $260 \mathrm{~nm}$ of benzene diazonium salt has an intramolecular charge transfer character, the peak moves easily to a longer wavelength region by introducing an electron donating group to the para-position of benzene diazonium cation. We utilize this absorption peak in the photochemical process of coatings and resist systems. Therefore, the primary products in the photochemical decomposition of aryl diazonium salts are an aryl cation and a nitrogen molecule. In chemical amplification resist systems, the photochemically produced aryl cation may react with water in polymer coatings as well as at air interface and with such protic species as novolac, poly(vinylphenol), etc.

\section{The Products Originating From the Secondary Reactions of Phenyl Cations.}

When a water molecule had approached to a phenyl cation, the potential energy of the system comprising these species has decreased monotonously as indicated in Fig. 4 and a new molecule whose structure is shown in Fig. 5 was produced spontaneously. The newly produced molecule has the same structure which generates when a phenol molecule is protonated.

In the same way, when a methanol molecule as the representative of protic species approached to a phenyl cation, a protonated anisole was spontaneously generated [Fig. 6]. Since the hydroxyl groups of novolac and poly(vinylphenol) are more reactive with an aryl cation than methanol, a protonated ether may be produced spontaneously in resist systems.

In this section, we postulated that the electronically excited species in the singlet state of a phenyl cation is dissipated to the ground state before the secondary reaction takes place. Thus, the secondary reactions in the excited states including the triplet states remain for investigations.

\section{Newly Proposed Photochemical Proton Generation Mechanism From Aryldiazonium Salts}

From the results presented above, we can propose a new mechanism of photochemical proton generation mechanism as the reactions (10), (11) and (12), which will be more reasonable than the old mechanism comprised of the reactions (1) and (2).

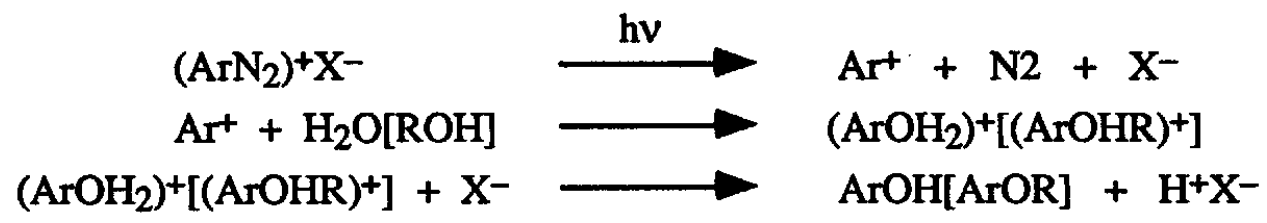

where $\mathrm{X}^{-}$is $\mathrm{SbF}_{6}, \mathrm{AsF}_{6}, \mathrm{PF}_{6}, \mathrm{BF}_{4}^{-}, \mathrm{CF}_{3} \mathrm{SO}_{3}^{-}$, etc. In the new mechanism, the anionic part $\mathrm{X}^{-}$ keeps its original structure throughout the proton generation process and acts as the proton accepter in the final stage. In the old mechanism, the structure change of $\mathrm{X}^{-}$played an important role in the proton generation process. As the chemical amplification reaction originates from the 


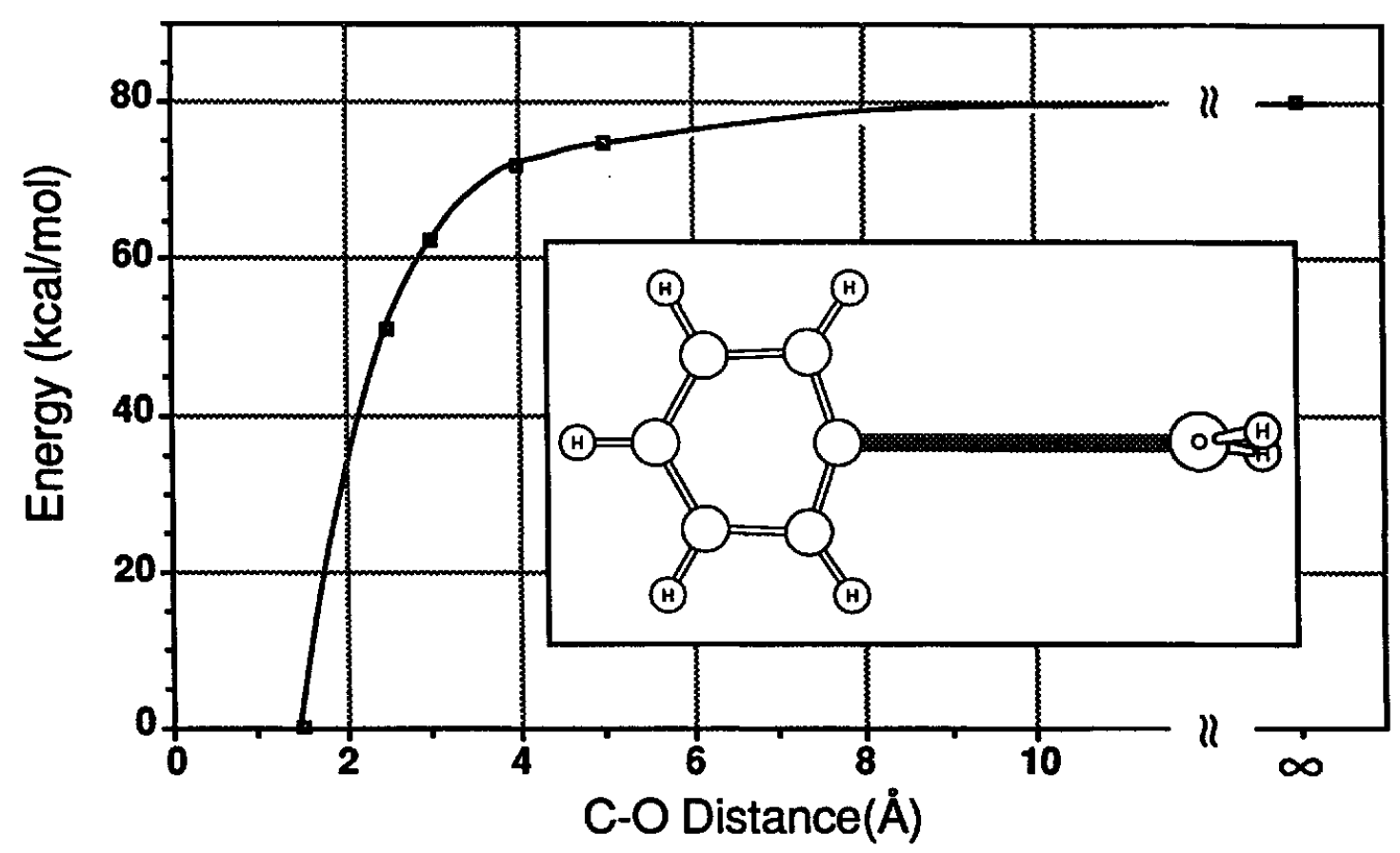

Fig. 4. Potential energy change along the reaction pathway when a water molecule approaches to a phenyl cation.

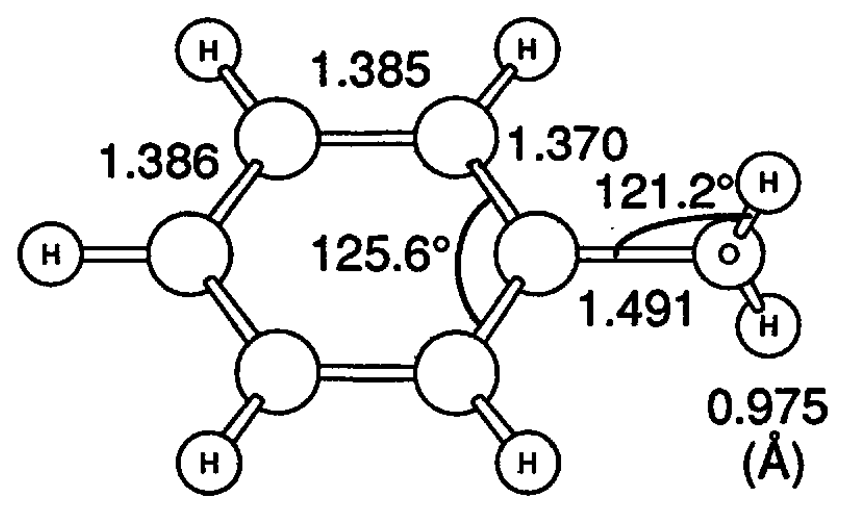

Fig. 5. The Optimized Structure of the protonated phenol produced from a spontaneous reaction of phenyl cation and water.

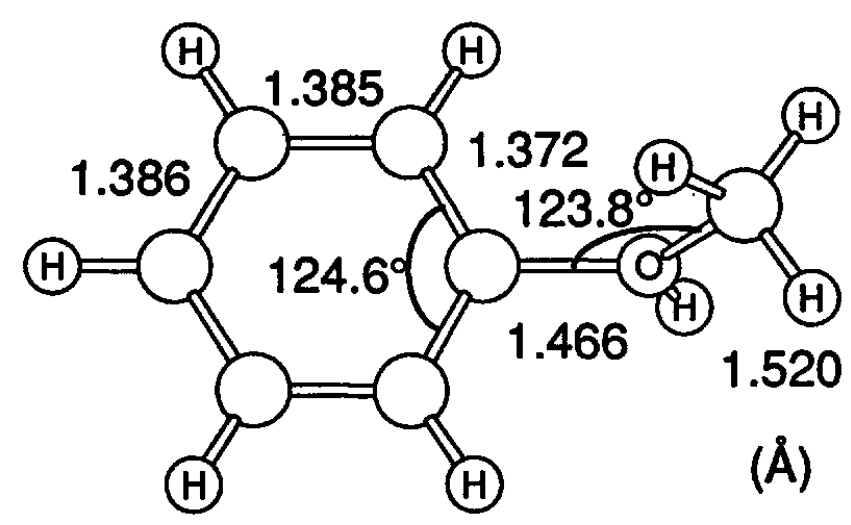

Fig. 6. The Optimized Structure of the protonated anisole produced from a spontaneous reaction of phenyl cation and methanol. 
photochemically generated acid $\mathrm{H}^{+} \mathrm{X}^{-}$in the reaction (12), we can conclude from this research that the sensitivity of an aryldiazonium salt as a photo-initiater is determined by the species of its anionic part $\mathrm{X}^{-}$and independent of the species of diazonium cation. This conclusion is consistent with experiments ${ }^{1)}$ where the sensitivity decreases in the order $\mathrm{SbF}_{6}>\mathrm{PF}_{6}>\mathrm{BF}_{4}^{-}$.

\section{In the Cases of Other Onium Salts}

Suppose that the photochemical proton generation mechanism of aryldiazonium salts is true in other onium salts, the mechanism for diaryliodonium and triarylsulfonium salts will be obtained when the reaction (10) is written as the reaction (10') for the former and as the reaction (10") for the latter.

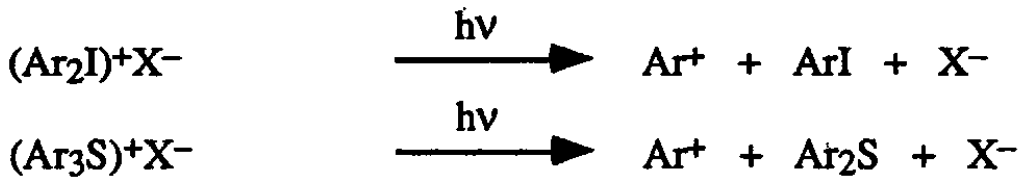

The difference between this newly proposed mechanism and the current mechanism is the primary product generated in the photochemical event; i.e., an aryl cation in the new mechanism and an aryl radical in the current mechanism. In the case of triarylsulfonium salts, the primary products are $\left(\mathrm{Ar}^{+}+\mathrm{Ar}_{2} \mathrm{~S}\right)$ and $\left(\mathrm{Ar}^{\bullet}+\mathrm{Ar}_{2} \mathrm{~S}^{+}\right)$for the former and the latter, respectively. In the first step for the elucidation of this problem, we intended to determine the potential energies of $\left(\mathrm{Ph}^{+}+\mathrm{Ph}_{2} \mathrm{~S}\right)$ and $\left(\mathrm{Ph} \cdot+\mathrm{Ph}_{2} \mathrm{~S}^{+}\right)$by ab initio molecular orbital calculations. The results are shown in Table 1 . In Table 1, the figures at the second row are the first ionization potential at the Hartree-Fock level calculations of each molecule whose name is indicated at the first row. The third, fourth and fifth rows show the improved values with the Moeller-Plesset perturbation theory in the second, third and fourth orders, respectively. Compared with the experimental values, the Moeller-Plesset perturbation theory gives better calculated values than the Hartree-Fock calculations. The reverse tendency in the improvement with the perturbation theory between $\mathrm{H}_{2} \mathrm{~S}\left[\mathrm{Me}_{2} \mathrm{~S}\right]$ and $\mathrm{Ph}$ - originates from the difference of the electronic structures of these species; i.e., the closed shell structure for the former and the open shell structure for the latter.

For this reason, the fourth order perturbation theory gives a larger values than that obtained by the Hartree-Fock calculation in the cases of $\mathrm{H}_{2} \mathrm{~S}$ and $\mathrm{Me}_{2} \mathrm{~S}$, but a smaller value in the case of PhThe sixth row shows the difference between the values obtained by the fourth order perturbation theory and the Hartree-Fock calculation. Because of the computer facility, no improved values of their first ionization potentials by the perturbation theory were obtained in the cases of $\mathrm{Ph}-\mathrm{S}-\mathrm{Me}$ and $\mathrm{Ph}_{2} \mathrm{~S}$. Assumed that the difference is $\sim 0.4 \mathrm{eV}$ in these cases $(0.4 \mathrm{eV}$ was estimated from $0.39 \mathrm{eV}$ of $\mathrm{Me}_{2} \mathrm{~S}$ ), the improved values are estimated to be $\sim 8.12 \mathrm{eV}$ for $\mathrm{Ph}-\mathrm{S}-\mathrm{Me}$ and $\sim 8.11 \mathrm{eV}$ for $\mathrm{Ph}_{2} \mathrm{~S}$, respectively. The value of $\sim 8.12 \mathrm{eV}$ for $\mathrm{Ph}-\mathrm{S}-\mathrm{Me}$ is very close to the experimental value $8.07 \mathrm{eV}$. 
Table I. Ionization Potentials of Various Sulfides and Phenyl cation a

\begin{tabular}{|c|c|c|c|c||c|}
\hline Molecule & $\mathrm{H}_{2} \mathrm{~S}$ & $\mathrm{SMe}_{2}$ & Ph-S-Me & Ph-S-Ph & Ph \\
HF & $9.61(9.35)^{\mathrm{c}}$ & 7.91 & 7.72 & 7.71 & 8.68 \\
MP2 & $9.92(9.93)$ & 8.31 & - & - & 7.17 \\
MP3 & $9.93(9.91)$ & 8.31 & - & - & 7.55 \\
MP4 & $9.92(9.91)$ & 8.30 & {$[\sim 8.12]$} & {$[\sim 8.11]$} & 7.41 \\
$\Delta$ (MP4-HF) & $0.31(0.56)$ & 0.39 & {$[\sim 0.4]$} & {$[\sim 0.4]$} & -1.27 \\
exp. b & $10.47(\mathrm{a}, \mathrm{v})$ & $8.71(\mathrm{v})$ & $8.07(\mathrm{v})$ & - & - \\
\hline E & $10.67(10.45)$ & 9.30 & 9.33 & 9.13 & 9.93 \\
Character & $\mathrm{S}_{3 \mathrm{p}}$ & $\mathrm{S}_{3 \mathrm{p}}+\mathrm{C}_{2 \mathrm{p}}$ & $\mathrm{S}_{3 \mathrm{p}}+\mathrm{C}_{2 \mathrm{p}}+\mathrm{Ph}_{2}$ & $\mathrm{Ph}_{2} \pi$ & $\pi$ \\
\hline
\end{tabular}

a) energies are obtained by ab initio MO calculations with 3-21G basis, and given in $\mathrm{eV}$ unit.

b) a or $\mathrm{v}$ mean adiabatic or vertical ionization potential.

c) numerals in parentheses ( ) are obtained by 3-21G* basis set.

d) HF: Hartree-Fock energy; MP2, MP3 and MP4: the second, the third and the fourth order Moeller Plesset perturbation energy

In this way, the following formulae are obtained:

\begin{tabular}{llll}
$\mathrm{Ph} \cdot+7.41 \mathrm{eV}$ & $=$ & $\mathrm{Ph}^{+}+\mathrm{e}^{-}$ \\
$+) \mathrm{Ph}_{2} \mathrm{~S}^{+}+\mathrm{e}^{-}$ & $=$ & $\mathrm{Ph}_{2} \mathrm{~S}+8.11 \mathrm{eV}$ \\
\hline $\mathrm{Ph}+\mathrm{Ph}_{2} \mathrm{~S}^{+}$ & $=$ & $\mathrm{Ph}^{+}+\mathrm{Ph}_{2} \mathrm{~S}+0.7 \mathrm{eV}$
\end{tabular}

Therefore, the potential energy of $\left(\mathrm{Ph}^{+}+\mathrm{Ph}_{2} \mathrm{~S}\right)$ is $0.7 \mathrm{eV}$ lower than that of $\left(\mathrm{Ph}^{\bullet}+\mathrm{Ph}_{2} \mathrm{~S}^{+}\right)$. This result seems to support the new mechanism than the current mechanism. However, the calculations performed only on the final products which participate the secondary reactions. The determination of the potential energy hypersurfaces (e.g., as indicated in Fig. 3 for benzene diazonium cation) remains for future research of diaryliodonium salts, triarylsulfonium salts, etc.

\section{Acknowledgment}

This work was partly supported by the Scientific Research Grant-in-Aid from the Ministry of Education, Science and Culture. The authors thank the Computer Center, Institute for Molecular Science, Okazaki, for the use of the M-680H/S-820 computer system and the library program GAUSSIAN 82. The computations were also carried out at the Computer Centre, the University of Tokyo, and the Computer Center, Chiba University. 


\section{References}

1) S. P. Pappas, J. Imaging Technol., 11 (1985) 145.

2) T. Yamaoka and H. Morita, Photosensitive Resins (Kankousei Jushi), Kyoritsu Publish. Tokyo (1988) p.19 (in Japanese)

3) For example, T. Yamaoka, Photopolymer Handbook, Technical Association of Photopolymers, Japan ed., Kogyo-chohsa-kai, Tokyo (1989) p.19

4) J. S. Binkley, M. Frisch, D. J. DeFrees, K. Raghavachari, R. A. Whiteside, H. B. Schlegel, G. Flueter and J. A. Pople : GAUSSIAN 82 (Carnegie-Mellon Chemistry Publication Unit, Pittsburgh, 1983)

5) M. Tsuda, S. Oikawa and A. Suzuki, Polymer Eng. Sci., 17 (1977) 390; M. Tsuda and S. Oikawa, J. Polymer Sci. (Polymer Chem. Ed.), 16 (1978) 3759; M. Tsuda, S. Oikawa and K. Kimura, Int. J. Quantum Chem., 18 (1977) 157.

6) S. Oikawa, M. Tsuda, A. Nogami, Y. Konno and Y. Fujimoto, Photogr. Sci. Eng., 27 (1983) 123. 